Research Article

\title{
Aroma Impact Compounds of Red Wines from La Mancha Region
}

\author{
J Antonio Delgado, M Ángel Ferrer*, Eva Sánchez Palomo and M Angel González-Viñas
}

Faculty of Chemical Sciences, Area of Food Technology, University of Castilla-La Mancha (UCLM), Avda. Camilo José Cela, 10, 13071 Ciudad Real, Spain

\section{Article Info \\ *Corresponding author: Miguel Angel González Viñas \\ Faculty of Chemical Sciences \\ Area of Food Technology \\ University of Castilla-La Mancha (UCLM), Avda \\ Spain \\ Tel: +00-34-926-295300 \\ E-mail: MiguelAngel.Gonzalez@uclm.es}

\section{Received: June 3, 2019 \\ Accepted: June 16, 2020 \\ Published: June 25, 2020}

Citation: Delgado JA, Ferrer MÁ, Palomo ES, González-Viñas MA. Aroma Impact Compounds of Red Wines from La Mancha Region. Madridge J Food Technol. 2020; 5(1): : 176-186.

doi: $10.18689 / \mathrm{mjft}-1000127$

Copyright: (c) 2020 The Author(s). This work is licensed under a Creative Commons Attribution 4.0 International License, which permits unrestricted use, distribution, and reproduction in any medium, provided the original work is properly cited.

Published by Madridge Publishers

\begin{abstract}
The aroma of six young red wines from minority grape varieties cultivated in La Mancha region has been studied by gas chromatography-olfactometry (GCO). The GC-O study revealed the presence of 102 aromatic notes in which 88 has been identified. Aroma compounds were classified according to their aroma descriptor similarity and summed in seven distinct aromatic series consisting on fruity, floral, sweet/toasted/caramel, spice, green/fresh/herbaceous, pungent/ acid/chemical/dry and others (liquorice, leather, tobacco and cooked vegetable). Although there were distinct quantitative differences among the wines relative aromatic series profile of the six wines were similar. Forty-five compounds of the components identified in the olfactometric analysis were quantified, 19 of which were found at concentrations higher than their corresponding odour thresholds. The strongest odorants in the CG-O experiments were similar in all cases, although significant differences in the intensity between the samples were noted. The components with the greatest capacity to introduce differences between these wines were beta-damascenone, ethyl dihydrocinnamate, gammabutyrolactone, 4-ethyl guaiacol, 4-vinylguaiacol, isoeugenol, syringol, guaiacol, ethyl caprate and eugenol. The correlation between the olfactometric intensities and the quantitative data is, in general, satisfactory if the olfactometric differences between the samples are high.
\end{abstract}

Keywords: Red wine; Gas chromathography-olfactometry; Quantitative analysis; GCMS; Sensory analysis.

\section{Introduction}

Wine aroma is formed by hundreds volatile compounds. More than 800 aroma compounds have been reported in wines, including higher alcohols, aldehydes, ketones, esters, acids, monoterpones and $\mathrm{C}_{13}$-norisoprenoids. The typical flavour is mainly due to volatile compounds coming from grapes. Grape aroma composition and its influence on wine aroma have been widely reviewed $[1,2]$.

Wine aroma compounds has been research over the last decades, and several comprehensive reviews [3-7] have been made, despite which there remain numerous unanswered questions about the role that certain components play in its aromatic profiles. However, the most of these compounds are not odour-active $[8,9]$ and their do not contribute to wine aroma, it not been possible to date to obtain a satisfactory reconstitution of their aroma, unlike the case of some white and rosé wines with simpler aroma [10-12].

Identification and ranking of odour active components in wines involves 
both human olfactory perceptions in concert with instrumental measurements. Gas chromatography with olfactometric detection (GC-O or GC-sniffing) is based on sensory evaluation of the eluate from the chromatographic column aimed at discovering the active odour compounds. The role of the detector is played by a properly educated person or a team of evaluating personnel. The human nose has been used as a gas chromatography (CG) detector almost since the introduction of $C G$, as the human nose is the most appropriate detector to monitor the presence of an odorant in effluent of a gas chromatograph [13-15].

The use of olfactometric techniques has revealed that the volatile fraction of young red wines contains several tens of odorants and that there are no remarkable qualitative differences between wines from different grape varieties $[16,17]$.

The GC-O methods that have been developed and applied can be categorized into three general approaches: extract dilution methods, intensity methods, and the detection frequency method. Dilution methods are based on sensory evaluations of stepwise aroma extract stepwise dilutions until no odour is perceived $[18,19]$. Component ranking is based on the assumption that the higher the dilution at which a compound can be detected by GC-O, the more significant is the odour component.

GC-olfactometry (GC-O) has been employed in the study of a wide variety of red [9,20-27] and white $[10,11,28]$ wines. These studies have shown that the vast majority of wine volatiles have little to no aroma activity and that aroma activity is limited to relatively few volatiles.

Different studies show that GC-O is highly sensitive for discovering differences between odorants levels in different samples [29-32]. In this study, the aroma of six wines made from red grape varieties cultivated in $\mathrm{La}$ Mancha region were research using GC-O analysis to characterize active odorants of these wines. A secondary objective was to determine which odorants can be responsible for the sensory proprieties of the wines.

\section{Materials and Methods}

\section{Wine simples}

Six grape varieties cultivated in La Mancha region (middle-southeast of Spain), harvested in their optimal ripening stage $\left(23-24^{\circ} \mathrm{Brix} ; \mathrm{pH} 3.4-3.6\right)$ and in good sanitary conditions, were used for winemaking process. Two batches of grapes (10 kg each) of Bobal, Cencibel, Moravía Agria, Moravía Dulce, Rojal and Tortosí grape varieties were elaborated in vats of $10 \mathrm{~L}$, with skin maceration until end of the alcoholic fermentation. Winemaking conditions were: addition of $100 \mathrm{mg} / \mathrm{L}$ of $\mathrm{SO}_{2}$, as $\mathrm{K}_{2} \mathrm{~S}_{2} \mathrm{O}_{7}$, after stemming and crushing, inoculation with Saccharomyces cerevisiae cerevisiae selected yeasts (UCLM 325, Fould-Springer), and fermentation temperature kept at $24^{\circ} \mathrm{C}$. Manual punching down was done twice a day. When the relative density reached a constant value the malolactic fermentation was induced by inoculation with Oenococcus oeni lactic acid bacteria (Lactobacter SP1; Laffort); this second fermentation finished in 2-3 weeks, as confirmed by TLC (Thin Layer Chromatography). Then the wines were racked. After 1 month, the wines were racked again, filtered through 1.2 $\mu \mathrm{m}$ membranes (Millipore, Bedford, MA, USA), bottled, and stored in a conditioned room kept at $16-18^{\circ} \mathrm{C}$.

\section{Reagents and standards}

Dichloromethane and methanol were purchased from Merck (Darmstadt, Germany). Ammonium sulphate and anhydrous sodium sulphate came from Panreac (Barcelona, Spain). Pure water was obtained from a Milli-Q purification system (Millipore, U.S.). LiChrolut EN resins were purchased from Merck. The Chemicals standards were supplied by Sigma-Aldrich, Firmenich, Panreac, Merck, Fluka, and Lancaster.

\section{Isolation of volatile compounds of wines}

The aroma compounds were separated by adsorption/desorption on preconditioned polypropylene-divinylbenzene cartridges [33] (LiChrolut EN, Merck, $0.5 \mathrm{~g}$ of phase). Fourty microliters $(40 \mu \mathrm{l})$ of 4-nonanol, used as an internal standard, were added to one hundred millilitres of wine which was then passed through the LiChrolut EN column at a flow rate of $1 \mathrm{ml} /$ min. The column was rinsed out with $50 \mathrm{ml}$ of pure water to eliminate sugars and other low-molecular-weight polar compounds.

Free fraction was eluted with $10 \mathrm{~mL}$ of dichloromethane. All dichloromethane extracts were cooled to $-20^{\circ} \mathrm{C}$ to separate the frozen water from the organic phase by decantation, and then dried over anhydrous sodium sulphate. Using nitrogen steam, the organic phase was concentrated to a final volume of $200 \mu \mathrm{l}$.

An Agilent gas chromatograph model $6890 \mathrm{~N}$ coupled to an inert Mass Selective Detector model 5973 equipped with a BP-21 capillary column $(60 \mathrm{~m} \times 0.25$ $\mathrm{mm}$ i.d.; $0.25 \mu \mathrm{m}$ film thickness) was used. Operating conditions were as follows: oven temperature program was: $70^{\circ} \mathrm{C}\left(5 \mathrm{~min}\right.$.) $-1^{\circ} \mathrm{C} / \mathrm{min}-95^{\circ} \mathrm{C}(10 \mathrm{~min}$. $)-2^{\circ} \mathrm{C} / \mathrm{min}$ - $200^{\circ} \mathrm{C}$ (40 min.). Injector and transfer line temperatures were $250^{\circ} \mathrm{C}$ and $280^{\circ} \mathrm{C}$, respectively. Mass detector conditions were: electronic impact (EI) mode at $70 \mathrm{eV}$; source temperature: $178^{\circ} \mathrm{C}$; scanning rate: $1 \mathrm{scan} / \mathrm{s}$; mass acquisition: $40-450 \mathrm{amu}$. One micro litre $(1 \mu \mathrm{l})$ was injected in split less mode. Carrier gas was helium $(1 \mathrm{ml} /$ $\min )$.

Retention time, Wiley mass-spectral library, and pure volatile compounds were used for identification, confirmation and preparation of standard solutions of volatile compounds. The relative response areas for each of the volatile compounds to the internal standard 
were calculated and interpolated in the corresponding calibration graphs. For the calibration, standard solutions were prepared in ethanol $(12 \% \mathrm{v} / \mathrm{v})$ with $5 \mathrm{~g} / \mathrm{L}$ tartaric acid and the corresponding internal standard in the same concentration as in the samples. Calibration curves were drawn for each standard at eight different concentration levels. All integrations were made on the total ion chromatogram. The measurements of all standards were performed in triplicate. When the authentic standard were not available the identification was based on the comparison with the spectral data of Wiley A library and the chromatographic dates of the literature, semi-quantitative analysis of these compounds were made assuming response factor equal to one.

\section{Analysis of mayor volatile compounds}

All major volatile compounds in wines were analyzed by direct injection [33] into a HP-5890 GC with a FID detector, using a CP-Wax-57 capillary column (50 m x $0.25 \mathrm{~mm}$ i.d.; $0.25 \mu \mathrm{m}$ film thickness). The oven temperature program was: $40^{\circ} \mathrm{C}\left(5 \mathrm{~min}\right.$.) $-4^{\circ} \mathrm{C} / \mathrm{min}-$ $120^{\circ} \mathrm{C}$. Injector and detector temperature were 250 and $280^{\circ} \mathrm{C}$, respectively. One micro litter $(1 \mu \mathrm{l})$ was injected in split mode. The carrier gas was $\mathrm{He}(0.7 \mathrm{ml} / \mathrm{min})$.

\section{Wine olfactometric analysis}

The organic extracts obtained by SPE were used in the GC-O analysis. Sniffing were carried out in an Agilent gas chromatograph model $4890 \mathrm{~N}$ equipped with a FID and sniffing port (SGE) connected by a flow splitter to the column exit. The column was BP-21 capillary column (60 $\mathrm{m} \times 0.25 \mathrm{~mm}$ i.d.; $0.25 \mu \mathrm{m}$ film thickness). The carrier gas was $\mathrm{He}(0.7 \mathrm{ml} / \mathrm{min})$.

One microliter of extract was injected in the split less mode, the split less time being $0.8 \mathrm{~min}$. The injector and detector temperatures were 250 and $280^{\circ} \mathrm{C}$ respectively.

The oven temperature was set at $70^{\circ} \mathrm{C}(5 \mathrm{~min})-.1^{\circ} \mathrm{C} /$ min $-95^{\circ} \mathrm{C}\left(10 \mathrm{~min}\right.$.) $-2^{\circ} \mathrm{C} / \mathrm{min}-190^{\circ} \mathrm{C}$ (40 min).

Five trained judges performed the GC-O study of the organic extract. Judges were described the odor of each compound elude and asked to measure the overall intensity of each odor using a structured scale (0-3) All samples were analyzed in duplicate.

The odorants were identified by comparison of their odors, chromatographic retention times and MS spectra with these of pure reference compounds.

\section{Sensory analysis}

Wines were evaluated in duplicate by a panel of 8 experienced wine-testers. Three wines were presented in each session, in coded standard wine-testing glasses according to standard 3591 [34] and covered with a watch-glass to minimize the escape of volatile components. Testing temperature was $10^{\circ} \mathrm{C}$. Assessment took place in a standard sensory-analysis chamber [35] equipped with separate booths. Wines were sniffed and tasted.
Physical-chemical standards were used to help define attributes [6]. The panellists used a $10 \mathrm{~cm}$ unstructured scale to rate the intensity of each attribute. The left-hand end of the scale was "attribute not perceptible" and the right-hand end was "attribute strongly perceptible".

\section{Odour activity values}

To evaluate the contribution of a chemical compound to the aroma of a wine the odour activity value (OAV) was determined. OAV is a measure of importance of a specific compound to the odour of a sample. It was calculated as the ratio between the concentration of an individual compound and the perception threshold reported in the literature [25].

\section{Statistical analysis}

Two-way ANOVA was carried out using the SPSS 22.0 for Windows statistical package.

\section{Results and Discussion}

The aroma of six red wines made from minority grape varieties cultivated in La Mancha region has been studied by quantitative GC-O analysis and subsequent chemical analysis. Relevant aroma sensory descriptors given by the expert panel are summarized in table 1 and the results from the GC-O study are given in table 2 .

The olfactometric experiment was carried out on the extracts obtained by SPE of wines on LiChrolut-EN resins. In the conditions used $(100 \mathrm{~mL}$ of wine percolated through a $0.5 \mathrm{~g}$ resin bed), the extraction of nearly all odorants is complete as it has been demonstrated in different analytical studies [36-39].

Table 2 lists the 102 different odor notes detected in the GC-O experiment, the identity of 88 of which could be identified, and the mean odor intensity scores given for the panel. An ANOVA (wine $\times$ sniffer) was carried out on these data, which allowed the determination of those odorants for which olfactometric intensity differed significantly according to the corresponding grape variety. Nevertheless, in none of the cases have found significant differences between the intensities awarded by the sniffers to the odorants of the wines what confirms that these work as a homogeneous group at the moment of expressing sensory judgments acting in the same way independently of the type of analyzed sample.

With over 102 aroma components of wide-ranging intensities and no single character impact compounds, it is difficult to predict the overall aroma impact of these wines from the sheer size of the data. To estimate overall wine aroma, the odor descriptors were grouped in different aromatic series and every compound is assigned to one or several aromatic series based on similar odor descriptor used. However, a few aroma components were difficult to assign a single category in that their sensory descriptors sometimes fit two aromatic 
series or were not obvious candidates for any category. The total intensities for every aromatic series were calculated as sum of the average individual intensities of each one of the compounds assigned to this series and the results were graphed in figure 1.

Intensity patterns in the category suggest that the major aroma characteristic of these wines would consist of fruity, sweet, floral and pungent. The sensory analysis of the wines realized by the panel of experienced wine-testers revealed that the most important descriptors in the aroma of these wines were red fruits, spices, leather, tobacco, liquorice and flowers (Table 1) with exception of the wines of elaborated with the variety Moravía Agria. Fruity was one of the series aromatic with major intensity (Figure 1). This is consistent with the large number of esters 17, identified and quantified by CG-MS. Sensory aroma profile of Moravía Agria wines reported floral and fruity character as two most important flavour characteristics.

Table 1. Sensory Descriptors given by the expert panel to the wines considered in this study.

\begin{tabular}{|c|c|c|c|c|c|}
\hline Bobal & Cencibel & Moravía Dulce & Moravía Agria & Rojal & Tortosí \\
\hline Clove & Liquorice & Leather & Floral & Red Fruit & Red Fruit \\
\hline Pepper & Red Frit Pepper & Tobacco & Lichi & Fresh & Pepper \\
\hline Leather & Fresh & Red Fruit & Fresh & Liquorice & Leather \\
\hline Tobacco & Herbaceous & Pepper & Clove & Clove & Tobacco \\
\hline Liquorice & & Liquorice & & Leather & Liquorice \\
\hline Red Frit & & & & Tobacco & \\
\hline
\end{tabular}

Table 2. Odor descriptors found in young red wines made from minority grape varieties cultivated in La Mancha region. Olfactory descripton, Chemical Identity and mean olfactometric intensities (0-3 scale eight judges).

\begin{tabular}{|c|c|c|c|c|c|c|c|c|c|c|c|}
\hline Odor descriptor & Identity & Bobal & Cencibel & $\begin{array}{l}\text { Moravía } \\
\text { Dulce }\end{array}$ & $\begin{array}{l}\text { Moravía } \\
\text { Agria }\end{array}$ & Rojal & Tortosí & average & Imax & Imin. & $\begin{array}{l}\text { Imax- } \\
\text { Imin }\end{array}$ \\
\hline Red friut & Ethyl isobutyrate & 2.33 & 2.67 & 2.33 & 1.67 & 1.67 & 0.67 & 1.67 & 2.67 & 0.67 & 2.00 \\
\hline Fruity & Ethyl butyrate & 3.00 & 1.67 & 2.33 & 1.33 & 3.00 & 1.67 & 1.83 & 3.00 & 1.33 & 1.67 \\
\hline Apple & Butyl acetate & 1.67 & 1.33 & 1.67 & 2.00 & 1.33 & 2.67 & 1.67 & 2.67 & 1.33 & 1.33 \\
\hline Fruity/sweet & n.i. & 0.00 & 0.67 & 0.00 & 0.00 & 0.00 & 0.33 & 0.33 & 1.67 & 0.00 & 1.67 \\
\hline Banana & Isoamyl acetate & 3.00 & 2.67 & 2.00 & 2.00 & 2.33 & 3.00 & 2.25 & 3.00 & 2.00 & 1.00 \\
\hline Cheese/fusel & Isoamyl alcohol & 3.00 & 3.00 & 3.00 & 3.00 & 1.67 & 3.00 & 2.46 & 3.00 & 1.67 & 1.33 \\
\hline Green & (E)-2-hexenal & 1.67 & 1.67 & 2.33 & 1.33 & 1.33 & 2.33 & 1.54 & 2.33 & 1.33 & 1.00 \\
\hline Ripe fruit & N.I. & 0.00 & 1.67 & 0.00 & 0.00 & 0.00 & 2.67 & 0.54 & 2.67 & 0.00 & 2.67 \\
\hline Dry fruits/ toasty & N.I. & 0.00 & 0.67 & 0.00 & 1.33 & 0.00 & 1.67 & 0.63 & 1.67 & 0.00 & 1.67 \\
\hline Green apple & Ethyl caproate & 2.67 & 2.67 & 2.67 & 1.67 & 2.33 & 1.33 & 1.88 & 2.67 & 1.33 & 1.33 \\
\hline Floral/green & Hexyl acetate & 1.33 & 1.33 & 2.33 & 2.33 & 2.00 & 1.33 & 1.50 & 2.33 & 1.33 & 1.00 \\
\hline Rancid & 4-methyl-1-pentanol & 2.00 & 0.67 & 1.33 & 0.67 & 1.33 & 1.00 & 1.08 & 2.00 & 0.67 & 1.33 \\
\hline Dry fruit & 3-methyl-1-pentanol & 0.33 & 1.67 & 1.00 & 0.67 & 1.00 & 0.67 & 0.75 & 1.67 & 0.33 & 1.33 \\
\hline Medicinal/acid & Ethyl Lactate & 3.00 & 1.67 & 2.33 & 2.33 & 1.67 & 2.00 & 1.88 & 3.00 & 1.67 & 1.33 \\
\hline Dry fruits/ toasty & N.I. & 1.33 & 0.67 & 0.00 & 1.67 & 2.00 & 1.33 & 1.08 & 2.00 & 0.00 & 2.00 \\
\hline Grass/green & 1-hexanol & 2.67 & 1.67 & 1.67 & 2.00 & 1.67 & 3.00 & 1.83 & 3.00 & 1.67 & 1.33 \\
\hline Green & (E)-3-hexen-1-ol & 2.33 & 1.33 & 1.00 & 2.67 & 1.33 & 1.33 & 1.58 & 2.67 & 1.00 & 1.67 \\
\hline Grass & (Z)-3-hexen-1-ol & 2.00 & 1.67 & 1.67 & 1.67 & 0.67 & 1.67 & 1.42 & 2.00 & 0.67 & 1.33 \\
\hline Herbaceous & (Z)-2-hexen-1-ol & 1.00 & 0.67 & 1.33 & 1.33 & 2.00 & 1.33 & 1.13 & 2.00 & 0.67 & 1.33 \\
\hline Mushroom & 3-octanol & 1.00 & 0.00 & 0.00 & 0.00 & 1.00 & 2.00 & 0.50 & 2.00 & 0.00 & 2.00 \\
\hline Green/floral & cis linalool oxyde furan & 0.00 & 0.00 & 2.00 & 0.67 & 0.67 & 1.00 & 0.75 & 2.00 & 0.00 & 2.00 \\
\hline flowery & $\begin{array}{l}\text { trans linalool oxide } \\
\text { furan }\end{array}$ & 0.00 & 0.00 & 1.67 & 1.67 & 1.00 & 0.67 & 0.88 & 2.00 & 0.00 & 2.00 \\
\hline Vinegar & Acetic acid & 2.67 & 2.00 & 1.67 & 1.67 & 0.67 & 1.67 & 1.50 & 2.67 & 0.67 & 2.00 \\
\hline
\end{tabular}


Madridge Journal of Food Technology

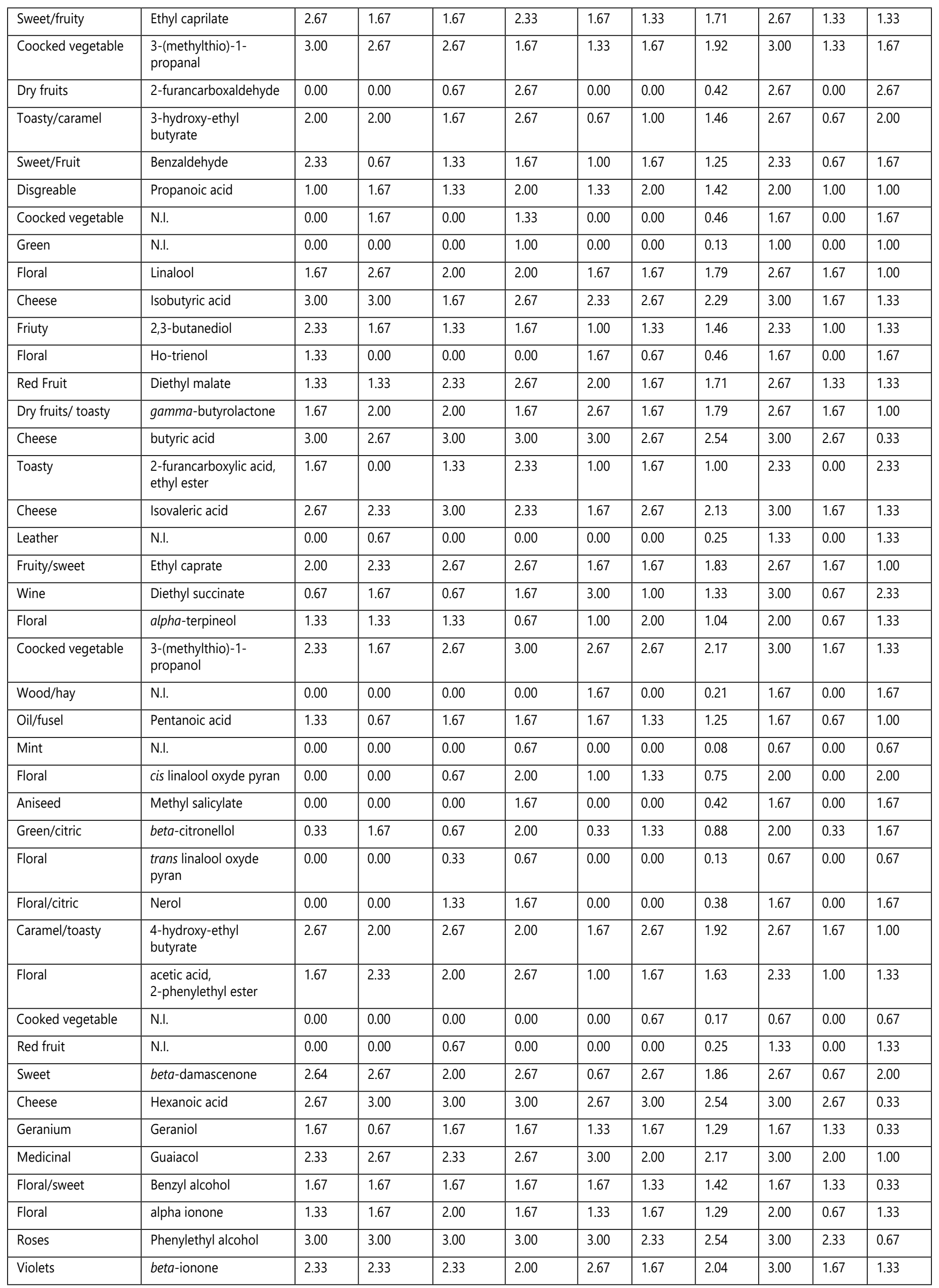


Madridge Journal of Food Technology

\begin{tabular}{|c|c|c|c|c|c|c|c|c|c|c|c|}
\hline Rancid/Dry & Heptanoic acid & 0.33 & 2.00 & 1.67 & 1.67 & 1.67 & 1.33 & 1.21 & 1.67 & 0.33 & 1.33 \\
\hline Fruity/sweet & delta nonalactone & 1.33 & 2.67 & 2.33 & 2.33 & 1.33 & 2.33 & 1.83 & 2.67 & 1.33 & 1.33 \\
\hline Acid & 2-hexenoic acid & 0.67 & 2.00 & 1.33 & 1.67 & 1.67 & 0.67 & 1.17 & 2.00 & 0.67 & 1.33 \\
\hline Medicinal & Phenol & 1.67 & 1.33 & 0.67 & 1.33 & 0.67 & 1.33 & 1.13 & 2.00 & 0.67 & 1.33 \\
\hline Sweet & Pantoic lactone & 1.33 & 2.00 & 2.00 & 2.00 & 1.33 & 1.33 & 1.46 & 2.00 & 1.33 & 0.67 \\
\hline Spice/floral & 4-ethyl guaiacol & 1.67 & 0.67 & 1.67 & 2.00 & 1.33 & 2.00 & 1.42 & 2.00 & 0.67 & 1.33 \\
\hline Fresh/mint/green & N.I. & 0.00 & 0.00 & 1.00 & 2.33 & 0.00 & 0.00 & 0.42 & 2.33 & 0.00 & 2.33 \\
\hline Strawberry/acid fruit & Diethyl malate & 2.67 & 1.67 & 2.00 & 2.33 & 1.67 & 2.00 & 1.88 & 2.67 & 1.67 & 1.00 \\
\hline Dry/oil & Octanoic acid & 2.33 & 3.00 & 3.00 & 3.00 & 3.00 & 3.00 & 2.54 & 3.00 & 2.33 & 0.67 \\
\hline Liquorice & N.I. & 0.00 & 1.67 & 2.67 & 0.00 & 0.00 & 0.00 & 1.00 & 2.67 & 0.00 & 2.67 \\
\hline Spices/Curry & 4-vinylguaiacol & 2.00 & 2.00 & 2.00 & 1.67 & 1.67 & 1.33 & 1.58 & 2.00 & 1.33 & 0.67 \\
\hline Clove/Spices & Eugenol & 1.33 & 2.67 & 1.67 & 2.67 & 1.67 & 1.67 & 1.71 & 2.67 & 1.33 & 1.33 \\
\hline Dry/Fusel & Nonanoic acid & 2.67 & 1.67 & 2.33 & 1.67 & 1.33 & 2.33 & 1.79 & 2.67 & 1.33 & 1.33 \\
\hline Floral & $\begin{array}{l}\text { 3,7-dimethyl-1,7- } \\
\text { Octadienol }\end{array}$ & 0.00 & 0.00 & 0.00 & 1.00 & 0.00 & 0.00 & 0.13 & 1.00 & 0.00 & 1.00 \\
\hline Toasty & $\begin{array}{l}\text { 2-(3H)-Furanone, } \\
\text { dihydro-5-propyl }\end{array}$ & 0.00 & 0.00 & 1.33 & 1.67 & 0.00 & 0.00 & 0.38 & 1.67 & 0.00 & 1.67 \\
\hline Toasty & Syringol & 2.00 & 1.67 & 2.00 & 2.00 & 2.33 & 1.33 & 1.67 & 2.33 & 1.33 & 1.00 \\
\hline Rancid/oil & Decanoic acid & 3.00 & 2.33 & 2.67 & 2.67 & 3.00 & 3.00 & 2.46 & 3.00 & 2.33 & 0.67 \\
\hline Coocked potato & $\begin{array}{l}\text { 3-methylthio propanoic } \\
\text { acid }\end{array}$ & 1.33 & 2.33 & 1.00 & 1.33 & 2.67 & 1.67 & 1.38 & 2.67 & 0.67 & 2.00 \\
\hline Green/floral & Geranic acid & 0.33 & 1.67 & 1.00 & 1.67 & 0.00 & 1.67 & 0.92 & 1.67 & 0.00 & 1.67 \\
\hline Floral & Isoeugenol & 1.00 & 0.67 & 1.33 & 1.67 & 1.00 & 1.33 & 1.08 & 1.67 & 0.67 & 1.00 \\
\hline Urine/animal & Benzoic acid & 1.00 & 2.00 & 1.00 & 1.33 & 1.67 & 0.67 & 1.04 & 2.00 & 0.67 & 1.33 \\
\hline Oil/Dry/Fusel & Dodecanoic acid & 1.67 & 3.00 & 1.67 & 2.67 & 2.67 & 2.67 & 2.17 & 3.00 & 1.67 & 1.33 \\
\hline Floral & Ethyl dihydrocinnamate & 0.00 & 1.67 & 2.00 & 2.00 & 0.67 & 1.67 & 1.21 & 2.00 & 0.00 & 2.00 \\
\hline Liquorice & N.I. & 0.00 & 0.00 & 2.67 & 2.33 & 2.67 & 0.00 & 0.96 & 2.67 & 0.00 & 2.67 \\
\hline Vanilla & Vanillin & 2.67 & 2.67 & 3.00 & 2.67 & 1.67 & 1.67 & 2.13 & 3.00 & 1.67 & 1.33 \\
\hline Honey/Vanilla & Methyl vanillate & 2.33 & 2.33 & 2.33 & 2.00 & 1.33 & 2.33 & 1.75 & 2.33 & 1.33 & 1.00 \\
\hline Vanilla/Sweet & Ethyl vanillate & 1.67 & 1.67 & 1.33 & 1.67 & 1.67 & 1.00 & 1.38 & 2.00 & 1.00 & 1.00 \\
\hline Spice & 3-oxo-alpha-ionol & 0.00 & 2.00 & 0.67 & 1.33 & 0.67 & 0.33 & 0.79 & 2.00 & 0.00 & 2.00 \\
\hline Sweet & Acetovanillone & 1.33 & 1.33 & 2.00 & 2.33 & 1.00 & 1.33 & 1.42 & 2.33 & 1.00 & 1.33 \\
\hline Dry & Tetradecanoic acid & 1.67 & 2.67 & 2.33 & 2.33 & 2.67 & 2.67 & 2.13 & 2.67 & 1.67 & 1.00 \\
\hline Floral & $\begin{array}{l}\text { 3-hydroxy-7,8-dihydro- } \\
\text { beta ionol }\end{array}$ & 0.00 & 0.00 & 1.00 & 1.00 & 0.00 & 0.00 & 0.25 & 1.00 & 0.00 & 1.00 \\
\hline Toasty/dry fruit & Zingerone & 0.00 & 2.00 & 2.33 & 2.33 & 1.33 & 2.00 & 1.25 & 2.33 & 0.00 & 2.33 \\
\hline Sweet/Polen & Methyl vanillil eter & 1.67 & 1.33 & 1.33 & 2.00 & 1.33 & 1.33 & 1.25 & 2.00 & 1.00 & 1.00 \\
\hline Floral & Cinnamic acid & 1.33 & 1.33 & 1.00 & 1.33 & 0.67 & 1.33 & 1.08 & 1.67 & 1.00 & 0.67 \\
\hline Dry & Hexadecanoic acid & 2.00 & 2.67 & 2.00 & 2.33 & 2.33 & 2.33 & 2.00 & 2.67 & 2.00 & 0.67 \\
\hline
\end{tabular}

N.I. Not identified

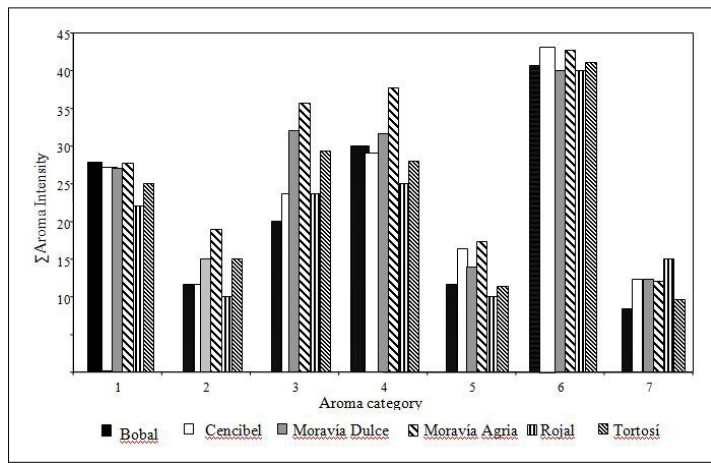

Figure 1. Aroma Intensities grouped by aromatic series descriptor. Aroma category: 1, Fruity; 2, Floral; 3, Fresh, green, herbaceous; 4, Sweet, toasted caramel; 5, spice; 6, pungent chemical, acid, fatty, dry; 7 , others (liquorice, leather, tobacco, cocked vegetable). 
The aromatic series 4 (Sweet, toasted, caramel) and 6 (purgent, chemical, fatty, dry) were also major aroma categories in the current study. These attributes were not detected in the sensory flavor profile studies of wines, nevertheless, some of the attributes include you in the aromatic series 7 (leather, liquorice, tobacco) and 5 (spice) whose total intensities were lower than those of the rest, if they were notes identified by the experienced wine-testers in the aromatic sensory profile of the wines. This can be due to that the values of total intensity in the different aromatic series were obtained as sum of the individual intensity of each one of the components without bearing in mind the rest of present compounds in the matrix of wine. Nevertheless when combined, synergy, suppression and matrix effects may alter the intensity of the descriptors, masking the descriptors of some aromatic series (series 4 y 6 ) and increasing the intensity of others odor descriptors (series 5 y 7 ).

The most notable olfactometric differences between the samples are summarized in table 3. The Bobal wine has a minimum content of 2-furancarboxaldehyde, cis and trans linalool oxide furan, cis linalool oxide pyran, ethyl dihydrocinnamate, zingerone, 3-oxo-alpha-ionol, and the four compounds unknown whose odor descriptors are ripe fruit, fresh and liquorice. Cencibel wine has a maximum content of ethyl isobutyrate, betadamascenone, zingerone and 3-oxo-alpha-ionol. Ethyl isobutyrate, zyngerone, beta-damascenone, ethyl dihydrocinnamate, cis linalool oxide furan and the two compounds with notes of liquorice are the most important compound of Moravía Dulce wine. The Moravía Agria wine has a maximum content of
2-Furancarboxaldehyde, zyngerone, 3-hydroxy ethyl butyrate, ethyl dihydrocinnamate and two unknown compounds with aromatic notes of liquorice and fresh. Diethyl succinate, 3-methyltio-propanoic acid and the unknown compounds with aroma notes of liquorice and toasty/dry fruit are the compounds with maximum intensities in Rojal wine. Finally, the Tortosi wine has a maximum content of zingerone, 3-octanol, betadamascenone and one unknown compound with ripe fruit notes.

\section{Odor activity values}

Table 4 completes the olfactometric study with the OAV of the quantified odorants using the odour threshold of the individual aroma compounds found in bibliography. Forty-five compounds of the components identified in the olfactometric analysis were quantified. According to the results each of these wines contains between 17 and 21 odorants at concentration above their threshold, similar values were obtained in different studies realized in white and rosé wines [7-25] although minors that the obtained in aged red wines [26]. As odor thresholds are affected by high imprecision and synergic, additive and antagonistic effects can take place, these values should not be taken as close boundaries but as an approximation to the number of odorants that constitute the odor of such wines.

There was a great similarity among the wines studied. The most potent odorants of each wine are practically the same only change the relative order from one sample to another.

Differencing components are those that have a more acute role in the perception of sensory differences

Table 3. Components showing the greasted differences in the olfactometric study.

\begin{tabular}{|c|c|c|c|c|c|c|}
\hline Identity & Bobal & Cencibel & Moravía Dulce & Moravía Agria & Rojal & Tortosí \\
\hline Ethyl isobutyrate & 2.33 & 2.67 & 2.33 & 1.67 & 1.67 & 0.67 \\
\hline N.I. & 0.00 & 1.67 & 0.00 & 0.00 & 0.00 & 2.67 \\
\hline 2-furancarboxaldehyde & 0.00 & 0.00 & 0.67 & 2.67 & 0.00 & $0.00 w$ \\
\hline N.I. & 0.00 & 1.67 & 2.67 & 0.00 & 0.00 & 0.00 \\
\hline N.I. & 0.00 & 0.00 & 2.67 & 2.33 & 2.67 & 0.00 \\
\hline Diethyl succinate & 0.67 & 1.67 & 0.67 & 1.67 & 3.00 & 1.00 \\
\hline Zingerone & 0.00 & 2.00 & 2.33 & 2.33 & 1.33 & 2.00 \\
\hline N.I. & 0.00 & 0.00 & 1.00 & 2.33 & 0.00 & 0.00 \\
\hline N.I. & 1.33 & 0.67 & 0.00 & 1.67 & 2.00 & 1.33 \\
\hline 3-octanol & 1.00 & 0.00 & 0.00 & 0.00 & 1.00 & 2.00 \\
\hline cis linalool oxyde furan & 0.00 & 0.00 & 2.00 & 0.67 & 0.67 & 1.00 \\
\hline trans linalool oxide furan & 0.00 & 0.00 & 1.67 & 1.67 & 1.00 & 0.67 \\
\hline Acetic acid & 2.67 & 2.00 & 1.67 & 1.67 & 0.67 & 1.67 \\
\hline 3-hydroxy-ethyl butyrate & 2.00 & 2.00 & 1.67 & 2.67 & 0.67 & 1.00 \\
\hline cis linalool oxyde pyran & 0.00 & 0.00 & 0.67 & 2.00 & 1.00 & 1.33 \\
\hline beta-damascenone & 2.64 & 2.67 & 2.00 & 2.67 & 0.67 & 2.67 \\
\hline 3-(methylthio)-propanoic acid & 1.33 & 2.33 & 1.00 & 1.33 & 2.67 & 1.67 \\
\hline Ethyl dihydrocinnamate & 0.00 & 1.67 & 2.00 & 2.00 & 0.67 & 1.67 \\
\hline 3-oxo-alpha-ionol & 0.00 & 2.00 & 0.67 & 1.33 & 0.67 & 0.33 \\
\hline
\end{tabular}

N.I. Not identified 
between wines. At the present time, this property con only is verified by means of sensory tests, although an approximation can be obtained by considering the variability in geometric terms of concentration or of concentrations normalized by their threshold (AOV) [25].

This fact is based in the relation between the intensity of an odour and their logarithm of the concentration of the odorant is in the most cases a sigmoid [40]. The central part of such a sigmoid can be represented by a linear function $(I=n \log C+b)$, which is the well-know Fechner law. After this law, differences in odor intensity observed between two solution of an odorant present at different concentration $\left(C_{1}\right.$ and $\left.C_{2}\right)$ are not related to the arithmetic difference of concentration but to the ratio of such concentration. As the OAV is a just a concentration normalized to the odor threshold, $\mathrm{OAV}_{\mathrm{s}}$ values cannot be compared by subtraction.

This approximation is show in table 5. After these result some important conclusions can be obtained. The components with the greatest capacity to introduce modifications in the aromatic profile of wines are betadamascenone, ethyl dihydrocinnamate, gammabutyrolactone, 4-ethyl guaiacol, 4-vinylguaiacol, isoeugenol, syringol, guaiacol, ethyl caprate and eugenol. The ratio between the $\mathrm{OAV}_{\mathrm{s}}$ was $>10$ in all cases. Whereas gamma-butyrolactone, ethyl caprate and ethyl dihydrocinnamate, are compounds principally produced during alcoholic fermentation by the amino acid metabolism, the mainly way of the beta- damascenone formation is the hydrolysis of their precursor whose accumulation is increase in warm climates $[41,42]$ therefore can be associated with varietal differentiation. Nevertheless the differences in the levels of phenols may be due to occasional contamination $[43,44]$.

A second group is made up of the components with a $O A V_{\text {maximum }} / O A V_{\text {minimum }}$ ratio between 2 and 10 . This group includes four alcohols ((Z)-3-hexen-1-ol, 3-methyltio-1-propanol, 3-methyl-1-butanol, phenylethyl alcohol), three esters (ethyl caprilate, ethyl caproate and phenyletyhl acetate) three acids (hexanoic, butyric and octanoic acid) and geraniol. Alcohols esters and acids are the most important compounds formed during the alcoholic fermentation therefore these compounds have not a lot of relation with the grape variety used in the wine-making process [16,45]. Nevertheless $C_{6}$ compounds, as (Z)-3-hexen-1-ol are principally formed during pre-fermentative operations and are linked with the ripening stage of the vintage, and the geraniol concentration, terpenic compound, is mainly related with the grape variety used $[1,2]$.

The last group is principally formed of the aromas generated in the metabolism of fatty acids by yeasts, such as fatty acids and ethyl esters. Some of these compounds have high $\mathrm{OAV}_{\mathrm{s}}$ but the maximum/ minimum OAV ratio is well below 2 , which confirms that the influence of grape variety on synthesis of these compounds is secondary importance.

Table 4. Odor activity values (OAV) of odorants found in studied young red wines.

\begin{tabular}{|c|c|c|c|c|c|c|c|c|}
\hline Compounds & Bobal & Cencibel & $\begin{array}{l}\text { Moravía } \\
\text { Agria }\end{array}$ & $\begin{array}{l}\text { Moravía } \\
\text { Dulce }\end{array}$ & Rojal & Tortosí & Mean & odor threshold \\
\hline beta-damascenone & 17.59 & 15.17 & 19.61 & $<0.1$ & 9.60 & 25.88 & 12.55 & 0.05 \\
\hline Ethyl dihydrocinnamate & 7.59 & 20.53 & 7.49 & 8.94 & $<0.1$ & $<0.1$ & 6.93 & 1.6 \\
\hline gamma-butyrolactone & 204.65 & 399.36 & 47.86 & 809.75 & 18.61 & 119.13 & 231.91 & 35 \\
\hline 4-ethyl guaiacol & 3.51 & $<0.1$ & $<0.1$ & $<0.1$ & 10.53 & $<0.1$ & 2.02 & 33 \\
\hline 4-vinylguaiacol & 0.74 & 50.24 & 3.08 & 17.00 & 1.16 & 8.23 & 12.01 & 40 \\
\hline Isoeugenol & 3.50 & 0.62 & 1.22 & 4.50 & $<0.1$ & $<0.1$ & 1.41 & 6 \\
\hline Syringol & 2.22 & 0.26 & 0.31 & 1.30 & $<0.1$ & $<0.1$ & 0.63 & 570 \\
\hline Guaiacol & 41.83 & 8.49 & 8.75 & 18.21 & 1.42 & 4.55 & 12.41 & 10 \\
\hline Ethyl Caprate & 0.10 & 1.46 & $<0.1$ & 0.37 & 0.33 & 0.27 & 0.42 & 200 \\
\hline Eugenol & 0.24 & 0.72 & 1.17 & $<0.1$ & 0.16 & $<0.1$ & 0.35 & 6 \\
\hline (Z)-3-hexen-1-ol & 0.21 & 0.66 & $<0.1$ & 0.41 & 0.52 & $<0.1$ & 0.30 & 400 \\
\hline 3-(methylthio)-1-propanol & 1.35 & 1.00 & 1.96 & 0.59 & 2.68 & 1.96 & 2.98 & 1000 \\
\hline Ethyl Caprilate & 84.87 & 136.79 & 30.35 & 70.40 & 90.51 & 42.71 & 88.13 & 5 \\
\hline Ethyl Caproate & 21.43 & 18.35 & 8.24 & 34.40 & 30.52 & 15.11 & 24.65 & 14 \\
\hline Hexanoic acid & 4.10 & 8.12 & 4.27 & 4.01 & 6.25 & 5.49 & 5.25 & 420 \\
\hline 3-methyl-1-butanol & 6.66 & 6.11 & 7.03 & 6.85 & 6.64 & 6.43 & 6.45 & 30000 \\
\hline Geraniol & 0.10 & $<0.1$ & $<0.1$ & $<0.1$ & 0.30 & $<0.1$ & $<0.1$ & 30 \\
\hline Phenylethyl alcohol & 4.53 & 5.63 & 1.96 & 4.24 & 2.51 & 3.35 & 3.60 & 10000 \\
\hline Acetic acid, 2-phenylethyl ester & 0.23 & 0.20 & 0.12 & $<0.1$ & 0.14 & $<0.1$ & 0.16 & 250 \\
\hline Butyric acid & 9.92 & 5.58 & 5.05 & 3.65 & 8.15 & 5.20 & 6.67 & 173 \\
\hline Octanoic acid & 3.45 & 6.41 & 2.95 & 3.21 & 4.97 & 4.39 & 4.73 & 500 \\
\hline Isovaleric acid & 63.05 & 36.32 & 49.82 & 65.38 & 71.17 & 50.24 & 55.14 & 33 \\
\hline Linalool & 3.55 & 3.92 & 3.31 & 1.13 & 1.86 & 1.80 & 2.33 & 15 \\
\hline Ethyl Lactate & 0.16 & 0.11 & $<0.1$ & $<0.1$ & 0.10 & 0.12 & 0.12 & 154636 \\
\hline Ethyl butyrate & 3.50 & 3.86 & 2.21 & 3.50 & 3.49 & 3.47 & 3.37 & 20 \\
\hline
\end{tabular}


Madridge Journal of Food Technology

\begin{tabular}{|l|l|l|l|l|l|l|l|l|}
\hline Acetovanillone & 0.15 & $<0.1$ & 0.13 & 0.15 & $<0.1$ & 0.16 & 0.10 & 1000 \\
\hline Isoamyl acetate & 1.11 & 1.22 & 1.68 & 1.12 & 1.11 & 1.10 & 1.21 & 30 \\
\hline Benzaldehyde & $<0.1$ & $<0.1$ & $<0.1$ & 0.13 & $<0.1$ & $<0.1$ & $<0.1$ & 350 \\
\hline Ethyl isobutyrate & 0.12 & 0.13 & 0.10 & 0.12 & 0.11 & 0.11 & 0.11 & 15 \\
\hline Vanillin & 1.49 & 2.10 & 0.25 & 1.04 & 0.11 & 0.49 & 1.03 & 60 \\
\hline Isobutanol & 1.07 & 0.76 & 1.18 & 1.02 & 1.03 & 0.87 & 0.96 & 40000 \\
\hline Isobutyric acid & 0.62 & 0.59 & 0.36 & 0.52 & 0.58 & 0.34 & 0.50 & 2300 \\
\hline Decanoic acid & 0.47 & 0.35 & 0.13 & 0.41 & 0.48 & 0.44 & 0.43 & 1000 \\
\hline Ethyl vanillate & 0.32 & 0.52 & $<0.1$ & 0.48 & 0.20 & 0.14 & 0.26 & 990 \\
\hline 1-hexanol & 0.24 & 0.40 & 0.17 & 0.25 & 0.40 & 0.38 & 0.30 & 8000 \\
\hline beta-citronellol & 0.11 & 0.21 & $<0.1$ & 0.14 & 0.15 & 0.16 & 0.13 & 100 \\
\hline Benzoic acid & $<0.1$ & $<0.1$ & $<0.1$ & $<0.1$ & $<0.1$ & $<0.1$ & $<0.1$ & 1000 \\
\hline 3-hydroxy-ethyl butyrate & $<0.1$ & $<0.1$ & $<0.1$ & $<0.1$ & $<0.1$ & $<0.1$ & $<0.1$ & 20000 \\
\hline delta nonalactone & $<0.1$ & $<0.1$ & $<0.1$ & $<0.1$ & $<0.1$ & $<0.1$ & $<0.1$ & 30 \\
\hline Diethyl succinate & $<0.1$ & $<0.1$ & $<0.1$ & $<0.1$ & $<0.1$ & $<0.1$ & $<0.1$ & 200000 \\
\hline Benzyl alcohol & $<0.1$ & $<0.1$ & $<0.1$ & $<0.1$ & $<0.1$ & $<0.1$ & $<0.1$ & 200000 \\
\hline Methyl vanillate & $<0.1$ & $<0.1$ & $<0.1$ & $<0.1$ & $<0.1$ & $<0.1$ & $<0.1$ & 3000 \\
\hline Hexyl acetate & $<0.1$ & $<0.1$ & $<0.1$ & $<0.1$ & $<0.1$ & $<0.1$ & $<0.1$ & 1500 \\
\hline Acetic acid & $<0.1$ & $<0.1$ & $<0.1$ & $<0.1$ & $<0.1$ & $<0.1$ & $<0.1$ & 200000 \\
\hline Propanoic acid & $<0.1$ & $<0.1$ & $<0.1$ & $<0.1$ & $<0.1$ & $<0.1$ & $<0.1$ & 8100 \\
\hline
\end{tabular}

Table 5. Compounds introducing the potential maximum differences in aroma, as measured by the quotient Maximun/Minimun OAV and Standard Deviation (in Logarithmic Scale Since Odor Intensity is proportional to logC) of the OAVs from the seven young red wines studied.

\begin{tabular}{|c|c|c|}
\hline Compounds & OAVmax/OAVmin. & $10 \mathrm{SD}(\log (\mathrm{OAV}))$ \\
\hline beta-damascenone & 259 & 101.09 \\
\hline Ethyl dihydrocinnamate & 205 & 100.96 \\
\hline gamma-Butyrolactone & 43.5 & 100.62 \\
\hline 4-ethyl guaiacol & 35.1 & 100.88 \\
\hline 4-vinylguaiacol & 25.1 & 100.64 \\
\hline Isoeugenol & 22.5 & 100.74 \\
\hline Syringol & 22.2 & 100.52 \\
\hline Guaiacol & 20.9 & 100.48 \\
\hline Ethyl Caprate & 14.6 & 100.39 \\
\hline Eugenol & 11.7 & 100.43 \\
\hline (Z)-3-hexen-1-ol & 6.63 & 100.33 \\
\hline 3-(methylthio)-1-propanol, & 5.65 & 100.40 \\
\hline Ethyl Caprilate & 5.31 & 100.26 \\
\hline Ethyl Caproate & 5.01 & 100.24 \\
\hline Hexanoic acid & 4.06 & 100.11 \\
\hline 3-methyl-1-butanol & 3.52 & 100.04 \\
\hline Geraniol & 2.96 & 100.18 \\
\hline Phenylethyl alcohol & 2.87 & 100.16 \\
\hline Acetic acid, 2-phenylethyl ester & 2.80 & 100.18 \\
\hline Butyric acid & 2.72 & 100.16 \\
\hline Octanoic acid & 2.61 & 100.16 \\
\hline Isovaleric acid & 1.96 & 100.10 \\
\hline Linalool & 1.96 & 100.28 \\
\hline Ethyl lactate & 1.83 & 100.11 \\
\hline Ethyl butyrate & 1.75 & 100.08 \\
\hline Acetovanillone & 1.56 & 100.09 \\
\hline Isoamyl acetate & 1.53 & 100.07 \\
\hline Benzaldehyde & 1.34 & 102.16 \\
\hline Ethyl isobutyrate & 1.28 & 100.48 \\
\hline Vanillin & 1.05 & 100.07 \\
\hline
\end{tabular}

The minimum OAV considered was 0.1

Madridge J Food Technol. 


\section{Conclusions}

The study presented here has show that the red wines made whit minority grape varieties cultivated in La Mancha region possess a large number of odorants detectable in the olfactometric studies, a fact that the complicates olfatograms excessively and can cause difficulties in their interpretation. Nevertheless, it can be said that the most important odorants of six red wines have been identified and the most of them quantified. The study has revealed that the evaluation of the intensity of the odorants using GC-O technique is a powerful method to detected differences between sensory aroma profile of wines.

\section{References}

1. Flanzy C. Enologia Fundamentos Cientificos y Tecnológicos. AMVMundi Prensa, Madrid, Spain. 2000.

2. Ribéreau-Gayon P, Glories Y, Maujean A, Dubourdieu D. Varietal Aroma. Handbook of Enology. The Chemistry of wine stabilization and treatments. Volume 2. England: Wiley. 2000.

3. Schneider P. Flavor composition of wines A review. CRC Crit Rev Food Sci Nutr. 1979; 12: 59-111. doi: 10.1080/10408397909527273

4. Nykanen L. Aroma of beer, wine and distilled alcoholic beverages. D. Reidel Publising Co.: Dordrecht, The Netherlands; 1982.

5. Nykanen L. Formation and occurrence of flavor compounds in wine and distilled alcoholic beverages. Am J Enol Viticult. 1986; 37: 84-96.

6. Noble AC. Wine Flavour. Understanding Natural Flavours. In: Piggot JR, Paterson A (eds). Blackie Academis Professional: Glasgow, UK; 1994: 228-242.

7. Aznar M, Lopez R, Cacho JF, Ferreira V. Identification and quantification of impact odorants of aged red wines from Rioja. GC-olfactometry, quantitative GC-MS, and odor evaluation of HPLC fractions. J Agric Food Chem. 2001; 49(6): 2924-2929. doi: 10.1021/jf001372u

8. Acree $T E$, Cunningham DG, Cunningham BJ. A procedure for the sensory analysis of gas chromatographic effluents. Food Chem. 1984; 14(4): 273-286. doi: 10.1016/0308-8146(84)90082-7

9. Ferreira V, Lopez R, Cacho JF. Quantitative determination of the odorants of young red wines from different grape varieties. J Sci Food Agric. 2000; 80(11): 1659-1667. doi: 10.1002/1097-0010(20000901)80:11<1659::AID-JSFA693>3.0.CO;2-6

10. Guth $\mathrm{H}$. Identification of character impact odorants of different white wine varieties. J Agric Food Chem. 1997; 45(8): 3022-3026. doi: 10.1021/ jf9608433

11. Guth H. Quantification and sensory studies of character impact odorants of different white wine varieties. J Agric Food Chem. 1997; 45(8): 3027-3032. doi: 10.1021/jf970280a

12. Ferreira V, Ortín N, Escudero A, López R, Cacho J. Chemical caracterization of Gernache rosé wines. Aroma extract dilution analysis, quantitative determination and sensory reconstitution studies. J Agric Food Chem. 2002; 50(14): 4048-4054. doi: 10.1021/ jf0115645

13. Fuller $\mathrm{GH}$, Steltenkamp $\mathrm{R}$, Tisserand $\mathrm{GA}$. The gas chromatograph with human sensor: perfumer model. Ann NY Acad Sci. 1964; 116: 711-724. doi: 10.1111/j.1749-6632.1964.tb45106.x

14. Pollien P, Ott A, Montigon F, Baumgartner M, Muñoz-Box R, Chaintreau A. Hyphenated headspace-gas chromatography-sniffing technique: Screening of impact odorants and quantitative aromagram comparisons. J Agric Food Chem. 1997; 45(7): 2630-2637. doi: 10.1021/ jf960885r

15. Ferreira V, Lopez R, Escudero A, Cacho J. The aroma of Grenache red wine: hierarchy and nature of its main odorants. J Sci Food Agric. 1998; 77(2): 259-267. doi: 10.1002/(SICI)1097-0010(199806)77:2<259::AIDJSFA36>3.0.CO;2-Q

16. Plutowaska B, Wardencky W. Application of gas chromatographyolfactometry (GC-O) in analysis and quality assessment of alcoholic beverages- A review. Food Chem. 2008; 107: 449-463. doi: 10.1016/j. foodchem.2007.08.058

17. Lopez R, Ferreira V, Hernandez P, Cacho J. Identification of odorants of young red wines made with Merlot, Cabernet Sauvignon and Grenache grape varieties: a comparative study. J Sci Food Agric. 1999; 79: 1461-1467. doi: 10.1002/(SICI)1097-0010(199908)79:11<1461::AIDJSFA388>3.0.CO;2-K

18. Acree $T E$, Cunningham DG, Cunningham BJ. A procedure for the sensory analysis of gas chromatographic effluents. Food Chem. 1984; 14(4): 273-286. doi: 10.1016/0308-8146(84)90082-7

19. Grosch W. Detection of potent odorants in foods by aroma extract dilution analysis. Trends Food Sci Technol. 1993; 4: 68-73. doi: 10.1016/0924-2244(93)90187-F

20. Miranda-Lopez R, Libbey LM, Watson BT, McDaniel MR. Odor analysis of Pinot noir wines from grapes of different maturities by a gas chromatography-olfactometry technique (Osme). J Food Sci. 1992; 57(4): 985-993, 1019. doi: 10.1111/j.1365-2621.1992.tb14339.x

21. Priser $C$, Etievant PX, Nicklaus $S$, Brun O. Representative champagne wine extracts for gas chromatography olfactometry analysis. J Agric Food Chem. 1997; 45(9): 3511-3514. doi: 10.1021/jf970123b

22. Escudero A, Cacho J, Ferreira V. Isolation and identification of odorants generated in wine during its oxidation: A gas chromatographyolfactometric study. Eur Food Res Technol. 2000; 211(2): 105-110. doi: $10.1007 /$ s002179900128

23. Fang $Y$, Qian $M$. Aroma compounds in Oregon Pinot Noir wine determined by aroma extract dilution analysis (AEDA). Flavour Fragrance J. 2005; 20(1): 22-29. doi: 10.1002/ffj.1551

24. Ferreira V, López R, Aznar M. Olfactometry and aroma extract dilution analysis of wines. In: Jackson JF, Linskens HF (eds). Analysis of Taste and Aroma. Molecular Methods of Plant Analysis. Volume 21. Springer. 2002: 89-122.

25. López R, Ortín N, Pérez-Trujillo JP, Cacho J, Ferreira V. Impact odorants of different young white wines from Canary Islands. J Agric Food Chem. 2003; 51(11): 3419-3425. doi: 10.1021/jf026045w

26. Culleré L, Escudero A, Cacho J, Ferreira V. Gas CromatographyOlfactometry and Chemichal Quantitative Study of the Aroma of Six Premium Quality Spanish Aged Red Wines. J Agric Food Chem. 2004; 52: 1653-1660. doi: 10.1021/jf0350820

27. Escudero A, Gogorza B, Melús MA, Ortín N, Cacho J, Ferreira V. Characterization of the aroma of a wine from Maccabeo. Key role played by compounds with low odor activity values. J Agric Food Chem. 2004; 52(11): 3516-3524. doi: 10.1021/jf035341।

28. Chisholm MG, Guiher LA, Vonah TM, Beaumont JL. Comparison of some French-American hybrid wines with White Riesling using gaschromatography olfactometry. Am J Enol Vitic. 1994; 45 (2): 201-212.

29. Ferreira V. Quantitative possibilities of gas chromatographyolfactometry with simple measurements of odor intensity. 10th Weurman Symposium. 2002.

30. van Ruth $\mathrm{SM}, \mathrm{O}^{\prime}$ Connor $\mathrm{CH}$. Evaluation of three gas chromatographyolfactometry methods: comparison of odour intensity-concentration relationships of eight volatile compounds with sensory headspace data. Food Chem. 2001; 74: 341-347. doi: 10.1016/S03088146(01)00142-X

31. Petersen MA, Ivanova $D$, Moller $P$, Bredie LP. Validity of ranking criteria in gas-chromatography olfactometry methods. 10th Weurman Symposium. 2002

32. Plutowaska B, Wardencky W. Application of gas chromatographyolfactometry (GC-O) in analysis and quality assessment of alcoholic beverages- A review. Food Chem. 2008; 107: 449-463. doi: 10.1016/j. foodchem.2007.08.058

33. Sánchez-Palomo E, Pérez-Coello MS, Díaz-Maroto MC, González-Viñas 
MA, Cabezudo MD. Contribution of free and glycosidically-bound volatile compounds to the aroma of muscat "a petit grains" wines and effect of skin contact. Food Chem. 2006; 95: 279-289. doi: 10.1016/j. foodchem.2005.01.012

34. UNE 87022. Análisis Sensorial. Utensilios. Copa para la degustación de vino. 1992.

35. UNE-EN ISO 8589. Análisis Sensorial. Guía General para el diseño de salas de cata. 2010.

36. Lopez R, Aznar M, Cacho J, Ferreira V. Quantitative isolation of minor and trace volatile compounds in wine by Solid Phase Extraction and Gas Chromatography with Mass Spectometric detection. J Chromatogr A. 2002; 966: 166-177. doi: 10.1016/s0021-9673(02)006969

37. Ferreira V, Jarauta I, Lopez R, Cacho J. Quantitative determination of sotolon, maltol and free furaneol in wine by solid phase extraction and gas chromatography-ion-trap mass spectrometry. J Chromatogr A. 2003; 1010: 95-103. doi: 10.1016/S0021-9673(03)00963-4

38. Ferreira V, Cullère L, Lopez R, Cacho J. Analysis of important odoractive aldehydes of wine through the Gas Chromatography-Mass Spectrometric determination of their O-(2,3,4,5,6-pentafluorobenzyl) oximes formed directly in the solid-phase extraction cartrige used for selective isolation. J Chromatogr A. 2004; 1028: 339-345. doi: 10.1016/j.chroma.2003.11.104

39. Ferreira V, Jarauta I, Ortega C, Cacho J. A simple strategy for the optimization of Solid-Phase-Extraction procedures through the use of solid liquid-liquid distribution coefficients. Application to the determination of aliphatic lactones in wine. J Chromatog. A. 2004; 1025: 147-156. doi: 10.1016/j.chroma.2003.10.086
40. Chastrette $M$, Thomas-Danguin $T$, Rallet E. Modelling the human olfactory stimulus-response function. Chem Senses. 1998; 23: 181-196. doi: 10.1093/chemse/23.2.181

41. Shure KB, Acree TE. Changes in the odor-active compounds in Vitis labruscana $\mathrm{cv}$. Concord during growth and development. J Agric Food Chem. 1994; 42: 350-353. doi: 10.1021/jf00038a022

42. Marais J, van Wyk CJ, Rapp A. Effect of sunlight and shade on norisoprenoids levels in maturing weisser Riesling and Chenin blane grapes and weisser Riesling wines. South African Journal of Enology \& Viticulture. 1992; 13: 23-32.

43. Chatonnet $P$, Dubourdieu $D$, Boidron JN, Pons M. The origin of ethyl phenols in wines. J Sci Food Agric. 1992; 60: 165-178. doi: 10.1002/ jsfa. 2740600205

44. Chatonnet P, Dubourdieu D, Boidron JN, Lavigne V. Synthesis of volatile phenols by Saccharomyces cerevisiae in wines. J Sci Food Agric. 1993; 62: 191-202. doi: 10.1002/jsfa.2740620213

45. Hernández Orte $\mathrm{P}$, Cacho JF, Ferreira V. Relationship between varietal amino acid profile of grapes and wine aromatic composition. Experiences with model solutions and chemometric study. J Agric Food Chem. 2002; 50: 2891-2899. doi: 10.1021/jf011395o 